\title{
COMMUTATIVITY OF TOEPLITZ OPERATORS ON THE BERGMAN SPACES OF THE UNIT DISK
}

\author{
ChaO Mei LiU
}

Abstract. In this paper we give some necessary and sufficient conditions that Toeplitz operators with special symbols commute with Toeplitz operators with harmonic symbols on the Bergman space.

Mathematics subject classification (2010): 47B35, 47B47.

Keywords and phrases: Bergman space, Toeplitz operator, Mellin transform, commutativity.

\section{REFERENCES}

[1] A. Brown And P. R. Halmos, Algebraic properties of Toeplitz operators, J. Reine Angew. Math. 213 (1963), 89-102.

[2] S. AXLER AND Ž. ČUČKOviĆ, Commuting Toeplitz, operators with harmonic symbols, Integral Equations Operator Theory 14 (1991), no. 1, 1-12.

[3] K. Stroethof, Essentially commuting Toeplitz operators with harmonic symbols, Canad. J. Math. 45 (1993), no. 5, 1080-1093.

[4] S. AXler, Ž AND N. V. RaO, Commutants of analytic Toeplitz operators on the Bergman space, Proc. Amer. Math. Soc. 128 (2000), no. 7, 1951-1953.

[5] ŽELJKo ČUČKOVIĆ AND N. V. RAO, Mellin transform, monomial symbols, and commuting Toeplitz operators, J. Funct. Anal. 154 (1998), no. 1, 195-214.

[6] Yufeng Lu And Chaomei Liu, Commutativity and hyponormality of Toeplitz operators on the weighted Bergman space, J. Korean Math. Soc. 46 (2009), no. 3, pp. 621-642.

[7] Iss AM LOUHICHI, LOVA ZAKARIASY, On Toeplitz operators with quasihomogeneous symbols, Arch. Math., 85 (2005), no. 3, 248-257.

[8] I. Louhichi And E. Strouse and Elizabeth and L. Zakariasy, Products of Toeplitz operators on the Bergman space, Integral Equations Operator Theory 54 (2006), no. 4, 525-539. 